\title{
Argentinos de París: razones de la aflicción y del desorden
}

\author{
Argentinians of Paris: reasons for affliction and disorder \\ Argentinos de Paris: razões da aflição e da bagunça
}

\section{Daniel Link}

UNIVERSIDAD DE bUENOS AIRES, UNIVERSIDAD NACIONAL TRECE DE FEBRERO, ARGENTINA

Profesor Titular de la cátedra de Literatura del Siglo XX en la Universidad de Buenos Aires y director de la Maestría en Estudios Literarios Latinoamericanos y del Programa de Estudios Latinoamericanos Contemporáneos y Comparados en la Universidad Nacional Tres de Febrero. Es autor de La lógica de Copi (Eterna Cadencia, 2017), Leyenda. Literatura argentina: cuatro cortes (Entropía, 2006), Clases: literatura y disidencia (Norma, 2005), El juego de los cautos. Literatura policial: de Edgar Allan Poe al caso Giubileo (La Marca, 1992), entre otros ensayos. Asimismo, es editor de Rodolfo Walsh. El violento oficio de escribir: obra periodística 1953-1977 (Planeta, 1995) y de Rodolfo Walsh. Ese hombre y otros papeles personales (Seix Barral, 1996), entre otros volúmenes. Correo electrónico:dlink@untref.edu.ar

\footnotetext{
Artículo de reflexión

Trabajo presentado en el panel "The New Otherwise: Renconceptualizing the Argentine Avant-Garde and Its Experimental Legacies" en el Congreso LASA 2015: Precariedades, exclusiones, emergencias (San Juan de Puerto Rico, 30 de mayo de 2015).

Documento accesible en línea desde la siguiente dirección: http://revistas.javeriana.edu.co 


\section{Resumen}

Entre el exilio de los años cincuenta y el de la dictadura argentina, un grupo de artistas expatriados en París, entre quienes se encontraban Copi, Cozarinsky y D'Alessio, se quedó en este destino utilizándolo como un campo inmanente de experimentación estética. $\mathrm{Al}$ alero de los conceptos de heterotopía, aflicción y deseo, el presente artículo se propone localizar en el punto de partida (Argentina) los predicados de esos vectores de desterritorialización, pero también identificar en el punto de llegada (París, no Francia), los modos de imaginar una comunidad errante, asocial, melancólica y, al mismo tiempo, futurista.

Palabras clave: cofradías masculinas; literatura y cultura argentina (siglo XX); París; heterotopía; deseo

\section{Abstract}

Between the exile of the 1950s

and that of the Argentine

dictatorship, a group of

expatriate artists in Paris (among whom were Copi, Cozarinsky, and D'Alessio) stayed in this destination, using it as an immanent field of aesthetic experimentation. Under the light of the concepts of heterotopia, affliction, and desire, this article proposes to locate at the starting point (Argentina) the predicates of these deterritorialization vectors. And, at the same time, it aims to identify at the arrival (Paris, not France), the ways of imagining a wandering, asocial, melancholic and yet, futuristic community.

Keywords: male brotherhoods; literature and Argentinian culture (20th century); Paris; heterotopia; desire

\section{Resumo}

Entre o exílio dos anos cinquenta e o da ditadura argentina, uma turma de artistas expatriados em Paris, entre quem encontrava-se Copi, Cozarinsky e D'Alessio, ficou nesse destino utilizando-o como campo imanente de experimentação estética. À luz dos conceitos de heterotopia, aflição e desejo, o presente artigo visa localizar no ponto de partida (Argentina) os predicados de esses vetores de desterritorialização, mas também identificar no ponto de chegada (Paris, não França), os modos de imaginar uma comunidade errante, insocial, melancólica e, ao mesmo tempo, futurista.

Palavras-chave: confrarias masculinas; literatura e cultura argentina (século XX); Paris; heterotopia; desejo

RECIBIDO: 15 DE JULIO DE 2016. ACEPTADO: 19 DE NOVIEMBRE DE 2016. DISPONIBLE EN LÍNEA: 29 DE DICIEMBRE DE 2017

Cómo citar este artículo:

Link, Daniel. "Argentinos de París: razones de la aflicción y del desorden". Cuadernos de

Literatura 21.42 (2017): 161-178. https://doi.org/10.11144/Javeriana.cl21-42.apra 
HACIA FINALES DE la década del sesenta y comienzos de la del setenta se produce un fenómeno que, si bien tuvo antecedentes, posee tal densidad que conviene estudiarlo aisladamente: la migración de un grupo de artistas (actores, directores de escena, músicos, escritores, pintores) que hacen de París su teatro de operaciones. ${ }^{1}$

El propósito de estas páginas es, por un lado, localizar en el punto de partida (Argentina) los predicados de esos vectores de desterritorialización y, por otro, localizar en el punto de llegada (París, no Francia), los modos de imaginar una comunidad errante, asocial, melancólica y, al mismo tiempo, futurista.

Germán Garrido ha investigado algunos aspectos de esa migración que es difícil de caracterizar (no responde exactamente a las lógicas conocidas de la diáspora, del exilio o de las migraciones) y, en homenaje a su trabajo pionero, titulo este artículo como aquel informe, que citaré más de una vez, ${ }^{2}$ a partir de una cita de La internacional argentina de Copi: "Siempre me he considerado como un argentino de París, es decir, como un ser apolítico y apátrida, pero no exactamente como un exiliado"(17). Garrido centró su investigación en las figuras del músico Carlos D’Alessio, ${ }^{3}$ que

1 La bibliografía sobre viajes estéticos es inmensa y tiene en David Viñas su piedra fundamental: De Sarmiento a Dios: viajeros argentinos a USA. Buenos Aires: Sudamericana, 1998.

2 El trabajo de Garrido se titula "Argentinos de París". La segunda parte de mi título, en cambio, repite parcialmente el título de un artículo de Beatriz Sarlo: "Razones de la aflicción y el desorden en Martín Fierro", Punto de Vista, II: 7 (Buenos Aires: noviembre de 1979). Aquí se trata, como allí, de la Ida y de la Vuelta (que no es sino un viaje diferente), aunque los viajes que evoco se parezcan más a la estancia de cinco años de Esteban Echeverría en París a partir de 1826. Naturalmente, todo sucede en un espacio completamente atópico (o heterotópico) y, por eso, por ejemplo, el primer acto de Cachafaz de Copi es más bien conceptual o ideológico, mientras que el segundo acto es más bien político. El primer acto define una ideología, el segundo apela a la acción política. Y así, Cachafaz invierte el Martín Fierro, donde "La ida" es una apelación a la acción mientras "La vuelta" es una integración en la ideología del Estado.

3 Un listado no exhaustivo de las partituras para teatro compuestas por Carlos D'Alessio incluye Luxe (1973, Alfredo Arias), L'étoile du Nord (1974, Alfredo Arias), Omphalos Hôtel (1975, Jean-Michel Ribes), L'Éden Cinéma (1977, Marguerite Duras), Succès (1978, Javier Arroyuelo y Rafael LópezSánchez). En cine, colaboró con La Femme du Gange (1974, Marguerite Duras), India Song (1975, Marguerite Duras), Des journées entières dans les arbres (1976, Marguerite Duras), Maîtresse (1976, Barbet Schroeder), Baxter, Véra Baxter (1977, Marguerite Duras), Le Navire Night (1979, Marguerite Duras), Les feux de la comtesse Dolingen de Gratz (1982, Catherine Binet), Hécate, maîtresse de la nuit (1982, Daniel Schmid), Parti sans laisser d'adresse (1982, Jacqueline Veuve), Les Enfants (1984, Marguerite Duras), Delicatessen (1991, Jean-Pierre Jeunet y Marc Caro). La última película que D’Alessio musicalizó fue Portrait de Borges en Aleph (1995, Edgardo Cozarinsky, 26'), que se estrenó después de su muerte en el Centre Georges Pompidou. 
escribió la partitura para India Song de Marguerite Duras ${ }^{4}$ y para un breve film de Edgardo Cozarinsky, entre tantas otras colaboraciones para el cine; en el grupo de teatro TSE, integrado por argentinos, que colaboró activamente en la producción de las obras teatrales de Copi; en el artista plástico Roberto Plate (amigo y escenógrafo de Copi); en el entrepeneur y productor artístico Javier Arroyuelo, el escritor y cineasta Edgardo Cozarinsky ${ }^{5}$, naturalmente, en Copi. ${ }^{6}$

4 Javier Arroyuelo fue el autor de la primera obra teatral que d'Alessio musicalizó en París, La comédie policière, un espectáculo hecho de restos paródicos del género policial. D’Alessio nació en Buenos Aires, donde estudió arquitectura y, al mismo tiempo, música. Antes de graduarse entró en una compañía teatral de variedades, donde compuso operetas y canciones de revista. En los años sesenta se mudó a Nueva York y, en 1972, poco después de la colaboración con Javier Arroyuelo, a París, donde murió en 1992. Arroyuelo vivía en París desde 1969 y fue el autor de las primeras obras que el grupo TSE montó en París. Sobre la música de D’Alessio ha dicho: "lo que venía haciendo d'Alessio con la música en Nueva York era lo mismo que hacíamos nosotros en teatro": un trabajo de montaje y desmontaje, de collage a la John Cage.

5 Se podría agregar a esa caprichosa lista al fotógrafo paraguayo Rolando Paiva (nació en París en 1942, sobrino nieto del presidente del Paraguay Félix Paiva e hijo de Emiliano Paiva Palacios, uno de los milicianos que fue a pelear en favor de la República Española y se instaló en París). En 1943, Emiliano conoció a una camarera polaca, Ángela Kot, con la que tuvo un hijo de nombre Ilya, más tarde Rolando Paiva. La historia parece tomada de una novela de Edgardo Cozarinsky, de quien Rolando Paiva fue íntimo amigo durante los años en que coincidieron en París. Paiva vivió desde sus 15 años hasta sus 27 en Buenos Aires, antes de instalarse en París. Además de una extraordinaria serie de fotografías del río Paraná, Paiva experimentó con antiguas técnicas fotográficas del siglo XIX (goma bicromada y rawling). Vivió en París treinta años, hasta su muerte, en 2003. Edgardo Cozarinsky escribió su necrológica para el diario Página/12, sobre la que volveremos.

6 Teresa Anchorena (vivió en Francia once años, entre 1973 y 1983, casada con Rolando Paiva) ha subrayado en varias oportunidades los parecidos entre la obra de Copi y la de Antonio Seguí, un "cordobés de París" (Córdoba, 11 de enero de 1934). A los 17 años, ayudado por su abuela materna, emprendió su primer viaje a Europa. Asistió como alumno libre a la Real Academia de Bellas Artes de San Fernando (Madrid) y a la École Nationale Supérieure des Beaux-Arts, París, ciudad donde se radicó definitivamente en 1963, después de haber trabajado en Córdoba en el diario Orientación (1954) y de haber vivido en México dos años (1958-1960, amigo de Siqueiros y vecino de Agustín Lara). Obtuvo, entre otros galardones, el Gran Premio de Artes Plásticas del Instituto Di Tella de Buenos Aires. A finales de 1982 comenzó a restaurar su casa en la localidad cordobesa de Saldán. De sus tempranas influencias (George Grosz, Otto Dix) conserva el gusto por una figuración expresionista irónicamente marcada. Su obra más celebrada muestra un mundo devenido teatro absurdo, donde las personas se mueven frenéticas en busca de un lugar (inexistente o imposible). Cuando Seguí llegó a París se instaló en el taller de Antonio Berni, hasta que el pintor le escribió "Dentro de seis meses voy a ir a París, así que buscate un atelier", y tuvo que instalarse en su célebre atelier suburbano, por donde han pasado desde Raúl Alfonsín hasta François Mitterrand. 
Uno de los puntos en común de esas experiencias es que su destino (siquiera transitorio) ya no es la utopía de un "París fabuloso" (Franco) que había encandilado a Julio Cortázar y otros de su misma generación (Pizarnik, por ejemplo) $)^{7}$ sino, como se verá más abajo, una heterotopía.

Javier Arroyuelo así lo reconoce en los testimonios que brinda a Garrido. Hacia finales de la década del sesenta, junto con Rafael López-Sánchez y Jorge Álvarez había fundado el sello Mandioca, ${ }^{8}$ apenas una pieza de un proyecto más ambicioso cuyo objetivo último era "transformar San Telmo en una suerte de West Village neoyorquino" (Garrido 3). Concurrentemente, Marta Minujín realizaba en el Instituto Di Tella una muestra llamada Importación-Exportación que "era un intento de importar la cultura de Greenwich Village (música pop, luces psicodélicas, incienso) a Buenos Aires, aunque no quedaba muy claro qué se exportaría a cambio" (King 219). ${ }^{9}$

¿Cómo explicar esas peregrinaciones que quedaron atrapadas entre dos experiencias mucho más prestigiosas, el exilio de los años cincuenta y el exilio de la Dictadura?

En una larga entrevista, Antonio Seguí contestó la pregunta " $[\mathrm{u}]$ sted se fue de la Argentina en plena etapa peronista. ¿La situación política tuvo algo que ver en su vida?" Tajantemente, afirma:

No, nunca fui peronista, no creo que mi viaje haya tenido nada que ver con la política. Tenía más que ver con una idea muy fuerte de mi generación para la cual la cultura pasaba más por Francia que por la Argentina. Nosotros leíamos más a Arthur Rimbaud y a Stéphane Mallarmé que a los autores nacionales. (Citado en Ventura 12)

Y, luego, ante la pregunta "¿[p] or qué está en París?" responde:

Porque París fue el lugar donde pude desarrollar lo que tenía ganas de hacer. Y el único donde pude expresar mi pasión con más tranquilidad. Antes había estado en Buenos Aires, y fue una experiencia nada gloriosa para mí. (Citado en Ventura 14)

7 El desencanto de Pizarnik respecto a París se deja leer en varias partes de su archivo (el Diario, la correspondencia), en los que opone el París de su primer viaje al de los sucesivos, en los que encuentra la ciudad ya sometida a la lógica de las ciudades en la era del capitalismo multinacional.

8 Fue el sello que editó el primer disco de Manal, por ejemplo.

9 Los finales de la década del sesenta condensan, además de Mayo del 68 y el Cordobazo, los sucesos de Stonewall. 
Mariana Bustelo, antes que Germán Garrido, llamó la atención sobre ese hiato que no ha concitado la suficiente atención de la crítica ${ }^{10}$ :

Puede trazarse una línea entre el viaje de los años 60 y el exilio producido por la dictadura, ya que en ambos casos los escritores se van de su país buscando mayor libertad. Sin embargo, en el primer periodo la búsqueda de libertad no está regida preponderantemente por aspectos políticos, sino de libertad estética, sexual y social a través de lo cual el escritor desarrolla una visión crítica de su país y su literatura. (Bustelo 42)

Germán Garrido desarrolla esa conclusión hasta sus últimas consecuencias en relación con la variable (que, en algún sentido, determina su corpus) que privilegia la interrogación de la comunidad sexual y, por eso, Garrido oscila entre La internacional argentina y El baile de las locas como denominaciones de los procesos que analiza. En ese sentido, la matriz del viaje que permitiría explicar estas identidades flotantes, entre lo nacional y lo cosmopolita, tendría que ver con una variable propiamente oikonómica (en el sentido que Agamben da a ese término [el ámbito de lo privado, que se resiste a ser conceptualizado en términos de macropolíticas]).

Garrido cita una entrevista a Rodríguez Arias:

En 1966, iba al Di Tella y un policía me paró de repente: "Usted no pasa más por acá. Yo estoy acá los días lunes, martes...". Me dio los horarios y me dijo que, si me veía de nuevo, me metía en cana. En ese momento pensé: esto se acabó. Si la represión podía expresarse de una manera tan natural, entonces estábamos llegando al máximo. Lo increíble es que, minutos después de mi encuentro con ese policía, entro al Di Tella y veo al galerista norteamericano Leo Castelli, que estaba por esos días en Buenos Aires. (Citado en Garrido 11$)^{11}$

Esta perspectiva coincide con la mucho más citada de Copi, quien escribe en La internacional argentina, además de un encendido elogio de Seguí (uno de los "grandes pintores argentinos del siglo"):

En el extranjero, formando parte del grueso de las tropas que Nicanor Sigampa designaba con el nombre de Internacional Argentina, estábamos

10 Bastuelo enumera los exilios de la década del cincuenta y de los primeros años de la del sesenta (estudiados por Molloy, Gasquet, Viñas) y con posterioridad a 1976 (estudiados por Campra, Cymerman, Oliveira-Cézar, además de la enorme masa testimonial).

11 Leo Castelli promocionó los grandes nombres del pop art norteamericano. 
nosotros, que habíamos huido, no de la dictadura militar, sino de todo lo que hacía posible su existencia en la sociedad argentina: la hipocresía católica, la corrupción administrativa, el machismo, la fobia homosexual, la omnipresente censura hacia todo [...] Pero supongo que esas categorías pertenecen al pasado. (Copi, Internacional 12 )

Sería imposible corregir una coma a las conclusiones de Garrido y por eso prefiero ampliar el corpus o, si se prefiere, las experiencias consideradas, para iluminar el asunto desde otra perspectiva que permita pensar las decisiones personales (irse a otra parte) en relación con un destino (París) como un campo inmanente de experimentación estética (o, lo que es lo mismo, ética).

Como bien reconocen los historiadores, ${ }^{12}$ la década del setenta es para los argentinos una década "larga". Más allá de las dificultades metodológicas con las que se topa la historiografía para aislar el periodo, los analistas y críticos de la cultura y el arte se enfrentan además con el peligro de articular mecánicamente procesos fácticos y producciones simbólicas. La peculiar conformación de la cultura argentina (su modernidad relativa y excéntrica) hace que muchos de los temas y problemas de los años sesenta y setenta aparezcan tematizados en experiencias estéticas y literarias bien anteriores.

"Casa tomada" (1946), de Julio Cortázar, parece estar tematizando, por ejemplo, una desintegración de géneros bien característica de la cultura y del arte pop. En ese cuento, todavía fantástico (aunque de un modo muy diferente a los ejercicios de Borges o Bioy), el narrador se define a sí mismo como "necesaria clausura de la genealogía asentada por los bisabuelos en nuestra casa" (284). Esa sensación de clausura, ese mal-estar en la casa, aparecerá marcado en el espacio cuando se desencadena el conflicto: el sector de los antepasados es tomado por fuerzas desconocidas. Del otro lado de la puerta clausurada quedan, dice el narrador, "mis libros de literatura francesa". La clausura de la genealogía es también la clausura de la biblioteca / la literatura / el arte, en cuya busqueda, podría plantearse como hipótesis, los exiliados de finales de los sesenta se afanan a toda costa.

12 Una versión previa de esta sección fue publicada con el título "Los setenta: crisis de la literatura y algunos nombres propios", en Entre el silencio y la violencia: arte contemporáneo argentino (Buenos Aires: arteBA Fundación, 2004). El volúmen es el catálogo de la muestra del mismo nombre organizada por la Fundación arteBA y Espacio Fundación Telefónica [Buenos Aires, 26 de noviembre de 2004 al 13 de marzo de 2005]). 
Sabemos que lo siniestro es constitutivo de la literatura fantástica, así como sabemos que el tercermundismo es característico de la cultura de los años sesenta. Es recién entonces cuando el Orbis tertius postulado veinte años antes por Borges, en "Tlön, Uqbar, Orbis Tertius", da paso al Tercer mundo, lo que nos permitiría pensar el peculiar cosmopolitismo de esos expatriados de comienzos de los setenta como una variante del "cosmopolitismo del pobre" definido por Silviano Santiago.

Más allá de la verosimilitud que otorguemos a la interpretación más cristalizada de "Casa tomada" (la invasión como el avance de la masa peronista, ganando espacios frente al agotamiento de la burguesía, según Sebreli), ${ }^{13}$ lo cierto es que las ficciones de Cortázar tienen una relación intensa con el acontecimiento peronista ("Las puertas del cielo", Los premios), que sería decisivo para definir el exilio de Julio Cortázar (y el de sus contemporáneos), pero tal vez no el de la generación siguiente.

Lo mismo puede decirse de textos posteriores como Operación masacre, El fiord o La traición de Rita Hayworth, que corresponden a otra formación imaginaria, en la cual los conflictos planteados por la política ya han sido resueltos o proyectados en otra dirección. En 1957, Rodolfo Walsh publicó la primera edición en libro de Operación masacre, una "novela policial para pobres", como la caracterizó Ángel Rama: en todo caso, un libro que desestabiliza definitivamente los géneros literarios a partir de un trabajo extremadamente complejo entre la ficción y la no ficción. Escrito como una investigación periodística y publicado como tal en diferentes episodios, al alcanzar el libro, Operación masacre se transforma en otra cosa, en un producto de los tiempos: se trata de un non-fiction (antes aún de que el non-fiction fuera codificado por algunos autores norteamericanos) o de un testimonio, en la línea de los grandes libros testimoniales latinoamericanos; Operación masacre pertenece de hecho y de derecho al universo de la literatura y así es leído.

$\mathrm{Al}$ año siguiente, Los dueños de la tierra de David Viñas mostraría estrategias explícitas de apropiación de ciertas tecnologías narrativas como el montaje, característico de las series estéticas que a partir de la década del

13 Para mayores detalles, véase el trabajo de Juan José Sebreli, Vida cotidiana y alienación, en el que señala: "Casa tomada' expresa fantásticamente esta angustiosa sensación de invasión que el cabecita negra provoca en la clase media". De paso, véase, también el texto de Carlos Gamerro, "Julio Cortázar, inventor del peronismo", en Ficciones Barrocas. Una lectura de Borges, Bioy Casares, Silvina Ocampo, Cortázar, Onetti y Felisberto Hernández. Buenos Aires: Eterna Cadencia, 2010, en el que se discute con fundamentos esa lectura. 
sesenta se convierten en hegemónicas. Esos libros, entonces, inaugurarían una serie de textos (entre los que Rayuela, con su perspectiva crepuscular, no es el menos notable) preocupados por el estado de las técnicas narrativas y, correlativamente, por ciertas cuestiones ligadas con la industria cultural y la posición de los intelectuales.

He propuesto, en más de una oportunidad, ${ }^{14}$ un cuento casi secreto de Viñas como la sutura entre los sesenta y los setenta. En "Sábado de gloria en la capital (socialista) de América latina" (1968), están los happenings, EUDEBA, el Di Tella, Primera Plana, el boom, Sartre, la revolución cubana y la televisión, en el delirio de un revolucionario, como se dice, de café. En ese cuento están todos los sujetos, instituciones, formaciones discursivas e ideológicas de la época puestos en evidencia, triturados, ridiculizados. Tan perfecta parece la descripción (un aleph pop) que no caben dudas de que los sesenta han sido clausurados.

Oscar Masotta, tal vez el teórico más emblemático de esos años, puntualiza en un prólogo escrito también en 1968 para Conciencia y estructura: "Algunos cambios históricos recientes han terminado por desbaratar las fiestas, por hacer evidente el absurdo" (9). Masotta se refería, seguramente, a Mayo del 68 (o a los avatares de la muestra "Tucumán arde") sin adivinar que el Cordobazo, que se produciría un año después, iba a confirmar su predicción, la misma que puede leerse en el cuento de Viñas, la misma que reconoce Antonio Seguí:

Hasta Mayo del '68, acá era pura fiesta. Con Copi desayunábamos fumando en el Café de Flore o en Les Deux Magots [...] Además, había un grupo muy importante de latinoamericanos con los que nos entendíamos: nos reuníamos en un bar cerca del metro Odeon donde siempre encontrábamos a alguien con quien conversar. (Ventura 13)

No es tanto la política de la revolución (el anhelo de un territorio sin peronismo, o sin dictadura) lo que lleva a tal o cual artista a armar sus valijas, sino la revolución de la fiesta y de la experimentación estética.

Beatriz Sarlo señaló, en respuesta a una entrevista que le hace John King, que, si bien "hay una conexión progresiva de una zona de la vanguardia con las preocupaciones políticas [...] esa conexión se produce más

14 Cfr. Link, Daniel. La chancha con cadenas. Buenos Aires: del Eclipse, 1994, y Leyenda. Literatura argentina: cuatro cortes. Buenos Aires: Entropía, 2006. 
aceleradamente después del golpe de Estado del 66, donde ya es la ideología de ese golpe la que concibe a la vanguardia como enemiga" (King 125) ${ }^{15}$.

En algún sentido, podría pensarse, los expatriados del periodo van a París en busca de algo que París no puede ofrecerles (y, me atrevería a postular, precisamente por eso): vanguardia, formas de vida experimentales, comunidades utópicas, experiencias urbanas radicales, fiestas (que suceden ya en Nueva York). Lo que encuentran es un apacible clima provinciano que les permite trabajar con tranquilidad y, en todo caso, un proceso de ascesis.

Antonio Seguí rechaza la caracterización de extranjero en París, se considera "de los dos lados, que es distinto. Me siento como en Córdoba y hago la misma vida", "Me hago traer la carne [...] Tengo el frigorífico lleno de carne de Córdoba", pero elude toda identificación nacionalitaria: no extraña la Argentina, pero sí "Córdoba. Yo tengo necesidad de volver a Córdoba cada tantos meses porque, si no, me falta el oxígeno", "fuera de Córdoba, y en Buenos Aires, me han hecho sentir tan extraño como en París", el tono irónico de su obra, dice, "sale de Córdoba. En casa siempre se hizo de la risa una ceremonia. Córdoba es una fábrica de chistes", "ser de Córdoba no es ser rioplatense. No me reconozco como nada; hago lo que puedo" (Ventura 11).

Ese no reconocerse, que es el efecto de las heterotopías, establece de inmediato un enrarecimiento del espacio y del tiempo y tiende, en última instancia, a aniquilar las fantasías concentracionarias del Estado como instancia de regulación de lo viviente.

Copi retomó esa obsesión anarco-nihilista de la tradición argentina, pero la llevó hasta sus últimas consecuencias, mucho más allá que los ejercicios humorísticos de Macedonio Fernández. La internacional argentina parece ocupar en la serie el sitio que dejó vacante el abandono de "El hombre que será presidente", la novela acerca de la campaña presidencial de Macedonio Fernández que Jorge Luis Borges y otros amigos comenzaron a escribir en 1927. Tal como lo recordaba Borges en 1960, su argumento parece glosar el de aquella novela:

15 En 1973, Noé Jitrik señalaba: "Lo que se llama cultura en un corte actual, ya sea la Extracción de la piedra de la locura, las Soledades o el Martín Fierro, implica un circuito de tres violencias, una de las cuales puede funcionar como ruptura: la del sistema que reprime (una violencia inicial) para permanecer, la del arte que trata de constituirse en acto de salida, la del sistema que trata de reinscribir". Años después, Josefina Ludmer, en el prólogo a la reedición de Cien años de soledad. Una interpretación señalaba: "el poder represivo politiza violentamente la cultura y al mismo tiempo enfrenta la politización alternativa (niega que politiza la cultura y atribuye ese gesto al enemigo)". 
El mecanismo de la fama le interesaba [a MF], no su obtención. Durante un año o dos jugó con el vasto y vago propósito de ser presidente de la República [... "Lo más necesario (nos repetía) era la difusión del nombre" [...] Convenía insinuarse en la imaginación de la gente de un modo más sutil y enigmático. Macedonio optó por aprovechar su curioso nombre de pila; mi hermana y algunas amigas suyas escribían el nombre de Macedonio en tiras de papel o en tarjetas, que cuidadosamente olvidaban en las confiterías, en los tranvías, en las veredas, en los zaguanes de las casas y en los cinematógrafos. Otra habilidad era congraciarse con las comunidades extranjeras $[\ldots]$ De estas maniobras más o menos imaginarias y cuya ejecución no había que apresurar, porque debíamos proceder con suma cautela, surgió el proyecto de una gran novela fantástica, situada en Buenos Aires, y que empezamos a escribir entre todos. (Si no me engaño, Julio César Dabove conserva aún el manuscrito de los dos primeros capítulos; creo que hubiéramos podido concluirlo, pero Macedonio fue demorándola, porque le agradaba hablar de las cosas, no ejecutarlas). La obra se titulaba El hombre que será presidente; los personajes de la fábula eran los amigos de Macedonio y en la última página el lector recibiría la revelación que el libro había sido escrito por Macedonio Fernández, el protagonista, y por los hermanos Dabove y por Jorge Luis Borges, que se mató a fines del capítulo noveno, y por Carlos Pérez Ruiz, que tuvo aquella singular aventura con el arco iris, y así de lo demás. En la obra se entretejían dos argumentos: uno, visible, las curiosas gestiones de Macedonio para ser presidente de la República; otro, secreto, la conspiración urdida por una secta de millonarios neurasténicos y tal vez locos, para lograr el mismo fin. Éstos resuelven socavar y minar la resistencia de la gente mediante una serie gradual de invenciones incómodas. La primera (la que nos sugirió la novela) es la de los azucareros automáticos, que, de hecho, impiden endulzar el café. A ésta la siguen otras: la doble lapicera, con una pluma en cada punta, que amenaza pinchar los ojos; las empinadas escaleras en las que no hay dos escalones de la misma altura; el tan recomendado peinenavaja, que nos corta los dedos; los enseres elaborados con dos nuevas materias antagónicas, de suerte que las cosas grandes sean muy livianas y las muy chicas pesadísimas, para burlar nuestra expectativa; la multiplicación de párrafos empastelados en las novelas policiales; la poesía enigmática y la pintura dadaísta o cubista. En el primer capítulo, dedicado casi por entero a la perplejidad y al temor de un joven provinciano ante la doctrina de que no hay yo, y él, por consiguiente, no existe, figura un solo 
artefacto, el azucarero automático. En el segundo figuran dos, pero de un modo lateral y fugaz; nuestro propósito era presentarlos en proporción creciente. Queríamos también que a medida que se enloquecieran los hechos, el estilo se enloqueciera; para el primer capítulo elegimos el tono conversado de Pío Baroja; el último hubiera correspondido a las páginas más barrocas de Quevedo. Al final el gobierno se viene abajo; Macedonio y Fernández Latour entran en la Casa Rosada, pero ya nada significa nada en ese mundo anárquico. En esta novela inconclusa bien puede haber algún involuntario reflejo de El hombre que fue fueves. (Borges 75-90)

Podría sostenerse, siquiera como hipótesis, que lo que le faltaba a Macedonio Fernández era una perspectiva, es decir: una distancia. A propósito de la muerte de su amigo Rolando Paiva, Edgardo Cozarinsky escribió:

Quisiera entender ese fenómeno de la distancia necesaria para ver, reconocer y apreciar lo próximo. Es la vieja fábula del pájaro azul, muy anterior a la adaptación simbolista de Maeterlinck, y que siempre me había inspirado rechazo por las connotaciones conformistas y populistas que el siglo XX le había adherido. Pero sus encarnaciones más elocuentes se han dado fuera de la escena o la página impresa. Borges, nacido en Buenos Aires, necesitó los años de adolescencia y primera juventud en Ginebra, Lugano y Mallorca, para descubrir al volver a su ciudad natal que ésta tenía la sustancia y los elementos del mito, y se aplicó a elaborarlo, con muy variadas entonaciones, a partir de ese primer libro emblemáticamente titulado Fervor de Buenos Aires. (73)

Pero Cozarinsky no solo sitúa el problema de lo propio y lo ajeno (de lo local y lo global en un umbral de mundo y de cosmopolitismo) en la estela de "El escritor argentino y la tradición", sino que caracteriza el París que ambos habitaron:

A menudo hablaba con Rolando del hartazgo que París suscita en quienes habíamos elegido vivir allí hace casi tres décadas, del desgaste de la imagen, prestigiosa en sentidos distintos para quienes alguna vez la habían percibido como tal, que como la luz de una estrella muerta sigue iluminando gracias a la discrepancia entre distancia y tiempo. Rolando sostenía que la formalidad de las relaciones sociales en Francia, gozada al principio como un alivio para quienes habíamos crecido en la francachela porteña, se tornaba asfixiante para quienes no habíamos buscado asimilarnos (escribir en francés, pensar en francés, sentir en francés). (74) 
Si París, esa estrella muerta de un cielo agonizante, tuvo para ellos algún significado, fue porque

nos permitía, inmigrantes sin el sello (hasta no hace mucho rentable) del exilio político, encontrar un hueco donde trabajar tranquilos, Rolando en la pintura y la fotografía, yo en la escritura y el cinematógrafo, sin angustia por alcanzar la aprobación de una sociedad cuya forma de funcionamiento refleja la calculada caducidad de la moda. (75)

Ni Seguí ni Cozarinsky ni Copi ni D’Alessio aceptan la etiqueta nacionalitaria. Copi responde, cada vez que puede "Soy un ciudadano argentino [porque] tengo pasaporte argentino", pero "No me criaron para ser argentino, porque yo no soy argentino" (Citado en Tcherkaski 35).

La obra de Copi (pero podría decirse lo mismo de la de Cozarinsky, hecha de jirones de recuerdos propios y ajenos, o de la de D'Alessio, que es un monumento funerario a la historia entera de la música) ${ }^{16}$ se funda en la tierra de nadie de la ensoñación, la imaginación y la memoria.

Copi, lo sabemos, deriva de ese triángulo misterioso una lógica del territorio (el Uruguay esquizo de "El uruguayo", la Défense en La torre de La Defensa, Las escaleras de Sacré Coeur, la selva, la luna, la estepa siberiana, los hielos árticos), una lógica del lenguaje y una lógica de las identidades trans (que no hay que detener simplemente en el análisis de la identidad sexual).

La potencia de París en estos artistas del no man's land ${ }^{17}$, es que, en su impotencia, irrealiza el mundo ${ }^{18}$. Eso permite explicar (más allá de las razones personales) que D'Alessio abandonara el centro real del mundo, Nueva York, por una quimera y un anacronismo.

16 A propósito de la obra de D’Alessio, el crítico Marc Phéline señala que "da la impresión de que ya la escuchamos, y sin embargo [...] no, no es". Phéline subraya este punto en "Portrait: La mémoire et la magie", artículo incluido en el booklet de Un vague extremement précis, compilado de diversas bandas sonoras y musicalizaciones realizadas por D'Alessio para filmes y obras de teatro de Marguerite Duras.

17 "He preferido colocarme en el no man's land de mis ensoñaciones habituales, hechas de frases en lengua italiana, francesa y de sus homólogas brasileña y argentina, entrecortadas con interjecciones castellanas, según la sucesión de escenas que mi memoria presenta a mi imaginación", escribió Copi en un manuscrito que se guarda en la abadía normanda de Ardenne, donde funciona el instituto francés de manuscritos, incluido en el compilado de Jorge Damonte.

18 Y lo que permite diferenciarlos de exiliados al estilo Cortázar o Pizarnik (que van hacia un centro caduco, pero centro al fin) o de los exiliados después de 1976, que, en rigor, no hacen sino preparar el regreso. 
París, en la perspectiva que aquí defenderemos para explicar las razones de la aflicción y del desorden en un grupo de expatriados a comienzos de la década del setenta, corta la cadena de los nombres, suspende la representación y, con ella, las alianzas y las filiaciones. Es, por su misma condición de ya-no-centro ("lo mismo que Córdoba", para Seguí; lo que permite trabajar "fuera de la calculada caducidad de la moda" para Cozarinski), una potencia de desclasificación y una heterotopía. No un lugar real, ni un espacio utópico (un emplazamiento sin lugar real), sino un diferencial ${ }^{19}$ que permite descubrirse ausente en el lugar en que se está, puesto que (por la vía de las endechas del recuerdo o de los fragmentos de lenguaje que asaltan los sueños y la irrealización del mundo) uno se ve allá (en otra parte, que es ninguna) y empieza a poner lo ojos sobre sí mismo y a reconstituirse allí donde (no) está. ${ }^{20}$

Pero no es un tema de identidad personal lo que se juega en este juego de espejos (por eso dejo de lado la disidencia sexual, las huidas del poder autoritario e incluso los gestos más propiamente políticos para subsumirlos en una ética perspectivista). ${ }^{21}$

Los gestos estéticos (completamente experimentales) que realizan los argentinos de París (no importa lo que hagan) no hacen sino subrayar el pueblo en falta, el Pueblo que se disuelve en la inminencia de un futuro que suspenda las jerarquías y los géneros (eso hace Cozarinski, en sus pasajes del cine documental al ensayo, eso hace D'Alessio con sus fragmentos de

19 Las utopías mantienen con el espacio real de la sociedad una relación general de analogía directa e inversa. Existen, por otro lado, lugares efectivos, lugares que están diseñados en la institución misma de la sociedad, que son una especie de contra-emplazamientos, una especie de utopías efectivamente realizadas en las cuales los emplazamientos reales, todos los otros emplazamientos que se pueden encontrar en el interior de la cultura, están a la vez representados, cuestionados e invertidos. Especies de lugares que están fuera de todos los lugares, aunque sean, sin embargo, efectivamente localizables, las heterotopías guardan con las utopías una relación de espejo (o que constituyen, con ellas, una experiencia mixta, medianera).

20 Para decirlo con Agamben, "Creo que sería extremadamente importante llegar a pensar de un modo nuevo la relación entre la potencia y el acto, lo posible y lo real. No es lo posible que exige ser realizado, sino la realidad la que exige volverse posible. Pensamiento, praxis e imaginación (tres cosas que no deberían ser jamás separadas) convergen en este desafío común: volver posible la vida" (Estado 16).

21 Los espejos, subraya Garrido, constituyen uno de los motivos principales de La guerre des pedes de Copi, cuyo narrador protagonista se llama esta vez Pico (Copi, en espejo). Luego de que Pogo, su pareja masoquista, es desfigurado por la travesti Conceiçao do Mundo, Pico opta por arrancar los espejos de la casa. Los procesos de desidentificación y las heterotopías se presuponen mutuamente. 
músicas perdidas, eso hace Paiva con su añoranza de un Paraná que es puro mito, el camino de los propios antepasados, y eso hacen los que participan del grupo Tse al proponer un teatro completamente al margen de todos los compromisos con cualquier tradición clásica o de vanguardia).

En El tiempo que resta leemos:

El pueblo no es ni el todo ni la parte, ni mayoría ni minoría. ${ }^{22}$ El pueblo es más bien lo que no puede jamás coincidir consigo mismo, ni como todo ni como parte, es decir, lo que queda infinitamente o resiste toda división, y que - a pesar de aquellos que gobiernan - no se deja jamás reducir a una mayoría o minoría. Y ésta es la figura o la consistencia que adopta el pueblo en la instancia decisiva, y como tal él es el único sujeto político real. (62)

Más allá del valor político de esa precisión, es metodológicamente pertinente en relación con el modo en que la literatura, la pintura, la fotografía, el cine sostienen lo viviente, en el periodo que aquí consideramos, en ese viaje irrealizante.

Los argentinos de París rechazan la identificación con una lengua, con un Estado, al mismo tiempo que rechazan todos los demás trascendentales (si subrayan maniáticamente un tipo de agenciamiento territorial con la ciudad: Córdoba, Buenos Aires, etc., es porque han elegido un modelo griego de soberanía). París, la heterotopía de comienzos de los setenta, es, en su impotencia, la potencia pura del pensamiento y de una cierta "filosofía reflexiva". ${ }^{23}$

Muy tempranamente, en 1967, Oscar Masotta señaló algunas características de la obra de Copi, que era por entonces obra gráfica, en el contexto de una cultura global, cuya lógica Masotta rechaza en su forma imperial-colonial, al mismo tiempo que subraya su potencia de desidentificación:

Copi, un dibujante argentino que vive en París, goza de una gran popularidad en Francia, a raíz seguramente de la filosofía reflexiva que subyace en sus dibujos: efectivamente, de cuadro a cuadro, hay en ellos poco desarrollo de la acción de tal manera que es el tiempo, un tiempo lento, sutilmente impregnado de humor, el objetivo o el tema de un estilo que

22 Por supuesto, lo sabemos por Deleuze, es un devenir.

23 He desarrollado este aspecto en relación con las filósofas travestis de Copi en "La voz (trans) del cielo latinoamericano", presentado en el panel "Politics of Love, Sex and Gender in the Southern Cone I: Queer Narratives", en el marco del Congreso LASA 2014, Democracy \& Memory (Chicago: 23 de mayo de 2014). 
concuerda bien con las exigencias de ciertas pautas culturales francesas, con un gusto bastante alejado del sentido concreto y cínico, por ejemplo, casi siempre vuelto hacia lo social, propio del humor inglés; y que tampoco coincide con las exigencias bastante menos abstractas de una Italia sobrepolitizada y que ha soportado la experiencia de la guerra en una situación completamente distinta a los demás países de Europa. Sin embargo, Copi es "traducido" ahora en Italia y comienza a ser conocido en Alemania y en los Estados Unidos [...] Si bien es cierto que esta universalización de la cultura, de la cual la historieta es un nuevo testimonio, tiene ante todo un valor positivo, puesto que tiende a borrar las "particularidades" nacionales: no es menos cierto que esa universalización puede ser utilizada - y lo es sin duda - como medio de influencia por los países que, por su estructura económica, se encuentran colocados en posición de centrales. (VII)

En efecto, en la lógica de Copi, la interrogación del tiempo y del espacio es tan decisiva como la interrogación de las imágenes en Cozarinski o la interrogación de la música en D’Alessio, porque se trata de minar todos los trascendentales para proponer, en un plano de inmanencia absoluta, un juego libre entre las categorías de tiempo y espacio (lo que explica, por ejemplo, el extraño funcionamiento de la muerte en los relatos y piezas teatrales de Copi), las imágenes como potencias vacías ("un hueco donde trabajar tranquilos") y los sonidos como fragmentos de un rompecabezas.

Para irrealizar el mundo hay que destruir las nociones temporales y espaciales, que son trascendentes a la percepción, pero también horadar todos los sistemas de clasificación, empezando por los más estigmatizantes, como la nacionalidad y la raza (las leyes de ciudadanía y de eugenesia, lo sabemos, vinieron de la mano).

En Loretta Strong, una de las piezas más raras y más difíciles de representar de Copi, ${ }^{24}$ Loretta es una astronauta perdida en el espacio exterior, luego de haber matado a su compañero, Steve Morton (esa exterioridad aparece reduplicada en otra nave con la cual Loretta se comunica, donde Linda estará matando a John Balling, al mismo tiempo que ella).

24 Edgardo Cozarinsky no conoció personalmente a Copi, pero en "Copi: Tres instantáneas y una postdata", incluido en su libro El pase del testigo (2000), postula una lectura memorable de esa pieza y de Las escaleras del Sacre Coeur. 
No voy a resumir el argumento, pero me detendré en un par de motivos: la figura hiperespacial (París, podría decirse, como cápsula perdida en el espacio exterior) y la imposibilidad de cumplir con la misión original del viaje (en la mitad de la cual la Tierra explota): "plantar oro" en Betelgeuse, proyecto que se ve frustrado por formas de vida monstruosas (hombres-monos de la Estrella Polar, plutonianos, murciélagos de oro con ojos de rubí, etc.).

En algún momento, entre tartamudeos, Loretta confunde L'or y l'aura (el oro y el aura). Es decir: establece un deslizamiento semántico de lo material a lo sublime ( propio nombre): L’or + État + Strong: el Oro, el Estado, la fuerza: capitalismo y esquizofrenia.

Aun en el espacio exterior, aun después del estallido de la Tierra, en el día después del final, aun en París, hay un habla desasignada de cualquier lugar, de todos los lugares, que vuelve a Loretta como una onda expansiva, una reverberación: “'Son los restos de la Tierra! ¿Habla? ¡Es mi propia voz que reverbera en los restos de la Tierra! ¿Tombuctú? dRío? ¿Los Alpes? ¿El Danubio? ¿Moscú? ¿Dallas? ¿Córdoba? ¿Lausana?" (Copi).

\section{Obras citadas}

Agamben, Giorgio. El tiempo que resta: comentario a la Carta de los Romanos.

2000. Trad. Antonio Piñero. Buenos Aires: Trotta, 2006. Impreso.

Agamben, Giorgio. Estado de excepción. 2003. Trad. Flavia Costa e

Ivana Costa. Buenos Aires: Adriana Hidalgo, 2004. Impreso.

Bastuelo, Mariana. "La palabra migrante: escritores argentinos en búsqueda de un territorio propicio para la creación". Amérique

Latine: Historie \& Mémorie 12 (2006): 1-43. Web.

Borges, Jorge Luis. Prólogos con un prólogo de prólogos. Buenos

Aires: Torres Agüero Editor, 1975. Impreso.

Copi. La internacional argentina. Trad. Alberto Cardín.

Barcelona: Anagrama, 1989. Impreso.

Cortázar, Julio. "Casa tomada". Cuentos Completos. Barcelona: Alfaguara, 2010. Impreso. Cozarinsky, Edgardo. El pase del testigo. Buenos Aires: Sudamericana, 2000. Impreso.

Damonte, Jorge, ed. Copi en Copi. París: Christian Burgois Editeur, 1990. Impreso.

Franco, Jean. "París, ciudad fabulosa". Novelistas hispanoamericanos

de hoy. Ed. Juan Loveluck. Madrid: Taurus, 1976. Impreso.

Garrido, Germán. "Argentinos de París". Informe de Adscripción a

la Cátedra Literatura del Siglo XX, Facultad de Filosofía y Letras,

Universidad de Buenos Aires (abril de 2008-abril de 2010), ts. 2012. 
Jitrik, Noe. "Arte, violencia, ruptura". Producción literaria y producción social. Buenos Aires: Sudamericana, 1975. 65-81. Impreso.

King, John. El Di Tella y el desarrollo cultural argentino en la década del 60. Buenos Aires: Ediciones Gaglianone, 1985. Impreso.

Massota, Oscar. Conciencia y estructura. Buenos Aires: Eterna Cadencia, 2014. Impreso.

Phéline, Marc. "Portrait: La mémoire et la magie", artículo incluido en el booklet del CD compilado por Marguerite Duras. Un vague extremement précis. Paris: 1997.

Sebreli, Juan José. Buenos Aires. Vida cotidiana y alienación.

Buenos Aires: Siglo XX, 1966. Impreso.

Tcherkaski, José. Habla Copi. Homosexualidad y creación. Buenos Aires: Galerna, 1998. Impreso.

Ventura, Any. "Antonio Seguí: el cordobés universal", entrevista en el diario La Nación. Buenos Aires (31 de octubre de 2004). http://www. lanacion.com.ar/649115-antonio-segui-el-cordobes-universal. Web.

Viñas, David. De Sarmiento a Dios: viajeros argentinos a USA.

Buenos Aires: Sudamericana, 1998. Impreso. 